\title{
OS DESAFIOS E AS PERSPECTIVAS DO ENSINO JURÍDICO NO SEMIÁRIDO BRASILEIRO
}

\author{
Ramon Rebouças Nolasco de Oliveira
}

Com grande sentimento de alegria e honra, registro minha gratidão pelo convite da equipe da Revista Estudantil Manus Iuris (REMI), do Curso de Direito da UFERSA, para proferir a palestra de lançamento da edição $n .^{\circ} 1$ deste periódico.

O tema proposto, pelos organizadores da REMI, para a presente palestra (“Os desafios e as perspectivas do ensino jurídico no semiárido brasileiro") indica a sensibilidade dos estudantes para perceber a árdua tarefa da Educação Jurídica e os horizontes contextualizados que se projetam para o processo de formação e de atuação cidadã dos profissionais do Direito.

O Eixo Temático idealizado para orientar os trabalhos do primeiro volume da Revista (“A importância do ensino, da pesquisa e da extensão nos cursos de graduação em Direito") foi elaborado com intuito de discutir o "tripé universitário" e celebrar os 10 anos do bacharelado em Direito da UFERSA.

O cenário da pandemia da COVID-19 nos impôs novas restrições e, como é comum ao brasileiro, notadamente, ao povo nordestino, superações e resistências são movimentos que constroem as respostas adequadas. O semiárido brasileiro tem sido um lócus privilegiado de expressões dessa natureza. Não é diferente quando tratamos da questão da educação jurídica.

Muito já se produziu, na academia, acerca de pesquisas sobre o “ensino jurídico". Pelo tom e formato desta apresentação, não convém, tampouco se faz necessário, trazer referências, nomes de autores e de obras. Estes materiais podem ser, facilmente, encontrados nos buscadores de produção científica, disponíveis na internet e acessíveis aos que se interessarem por aprofundar nas leituras.

Pensar "desafios" e "perspectivas" no "semiárido potiguar", necessariamente, exige atentar para as peculiaridades regionais que marcam nosso contexto. As condições socioeconômicas, a cena política, os aspectos culturais específicos, as formas de violações de direitos e as dificuldades para se garantir acesso à Justiça, neste ambiente, constituem elementos idiossincráticos.

Todavia, o estado da arte sobre a educação jurídica brasileira aponta para uma propalada “crise", que é generalizada, não sendo própria de uma ou outra região do país. Além disso, os meios de comunicação e as tecnologias da informação, nos últimos anos, têm conectado o semiárido nordestino aos demais territórios do Brasil e ao mundo, de tal forma que os problemas sociais e os impactos da e na formação jurídica passam a importar a todos os que interagem nessa rede.

Essa, digamos assim, "nacionalização" ou "globalização" das problemáticas não retira ou nega as 
características singulares do semiárido nordestino. Contudo, é possível identificar desafios e perspectivas comuns, que nos fazem pensar de modo "glocal" (local e global, ao mesmo tempo). Nesse enredo, é importante notar as contribuições que podemos produzir, enquanto sujeitos inseridos e envolvidos na práxis da educação jurídica nordestina. Ao mesmo passo, podemos beber de outras fontes e nos apropriarmos, com originalidade, das produções geradas em outros espaços.

Antes de citar, nominalmente, desafios e perspectivas, considero relevante tecer algumas notas pessoais sobre minha trajetória nessa chamada "educação jurídica". A biografia de uma pessoa carrega, com vivacidade e concretude, dimensões que auxiliam na compreensão de seu modo de pensar. No meu caso, como natural do semiárido nordestino, tendo cursado da graduação ao doutorado nesta região, na qual leciono atualmente, "senti na pele" alguns desafios próprios deste contexto.

Os 10 anos do Curso da UFERSA se confundem também com minha primeira década como Graduado em Direito. Enquanto este Curso nascia, eu passava de discente a egresso da instituição pública vizinha, a UERN. Encerrava o Curso certo da vocação acadêmica, mas sem ter ideias claras de como se desenvolveria o percurso. Ao ingressar como docente da UFERSA, em 2014, pude acompanhar a primeira turma de formandos.

Então, minha história como educador jurídico se confunde com a história da graduação em Direito da UFERSA. Os erros, os acertos, as surpresas positivas e negativas, que fazem parte da caminhada na trilha educacional, decorrentes de encontros, diálogos e aprendizagens mútuas com cada colega professor e aluno, foram forjando meu modo de ver ou tornando mais evidentes os desafios e as perspectivas que hoje consigo enxergar.

Durante minha graduação, experienciei o campo de estágio forense, a participação em eventos acadêmicos e a produção na iniciação científica, de forma bem incipiente, porém capaz de firmar convicções. Entre elas, a convicção de que o tripé universitário (ensino, pesquisa e extensão) é fundamental para uma formação mais sólida do bacharel em Direito. Ao seguir para um Mestrado em Ciências Sociais e Humanas, outra convicção que se estabeleceu foi da relevância da interdisciplinaridade para o preparo do graduado em Direito.

Com esse breve relato, já indico o que seriam, ao mesmo tempo, dois desafios e duas perspectivas: a formação jurídica marcada por reflexões e práticas interdisciplinares, e a vivência no ensino, na pesquisa e na extensão. Esses ingredientes têm o grande potencial de aproximar o Direito de outras áreas do conhecimento e da tradição, compartilhando saberes e métodos. As aprendizagens que se processam no ambiente da extensão, em suas variadas formas, e no desenvolvimento de pesquisas, empíricas e teóricas, modulam, com singularidade, a construção do egresso. Desse modo, o discente não fica limitado ao ensino tradicional, normativista e formalista.

Ao atuar com os estudantes, na extensão, na pesquisa e na prática jurídica, aprendi o quanto essas vivências são cruciais para formação humana no espaço universitário. No Direito, ainda, é comum a 
reprodução de modelos curriculares que enfatizam a memorização de conteúdos expostos, oralmente, pelo professor. Na prática extensionista e de pesquisa, a participação ativa dos sujeitos aprendizes traz outra dinâmica ao processo de aprendizagem.

Com o advento do vigente Plano Nacional de Educação, a extensão passou a ser obrigatória nos currículos dos cursos de graduação do país. Os ajustes nas matrizes para integralização do bacharelado em Direito poderão estimular práticas e consolidar itinerários formativos enriquecidos pela ação extensionista. $\mathrm{O}$ mesmo podemos dizer se houver mais investimento na pesquisa. O certo é que, com essas mudanças, podemos visualizar um horizonte também de desafios para implementação de novas metodologias no ensino do Direito.

Nesse passo, as chamadas metodologias ativas ou participativas convidam docentes e discentes a novas funções e atitudes no processo de ensinar-aprender. Na cena educacional proposta por essas metodologias, todos são atores, sem que haja meros coadjuvantes ou figurantes. Os papéis dos professores e dos alunos são dinâmicos. Não são estáticos, como seriam na educação bancária. Técnicas e recursos inovadores são bem-vindos, tornando a aula expositiva um dos meios, mas não mais o único ou o mais importante.

O tempo em sala de aula também passa a ser melhor aproveitado, de modo que o planejamento pedagógico projeta ações de aprendizagens extraclasse. A presença do professor passa a ter outro significando, quando este se reconhece como uma limitada fonte de conhecimentos, estimulando e orientando os aprendizes a como explorar bases de dados, selecionar e validar informações. Essa proposta também investe na autonomia dos sujeitos, assumindo que cada indivíduo tem suas formas particulares de aprender, de modo que a pluralidade epistemológica e metodológica deve integrar os ambientes educacionais.

Atualmente, vivemos a era da chamada educação, currículo ou aprendizagens por "competências". Bem definidas, as competências articulam conhecimentos, comportamentos e valores. Ou seja, os saberes (científicos e da tradição), as ações (atitudes e fazeres) e as posturas éticas (crítico-reflexivas) são vistos como elementos formativos indissociados. O cognitivismo, que enfatiza a aprendizagem intelectual e construtiva; o comportamentalismo, que destaca a ação externa e a interação indivíduo-sociedade (as repostas dos sujeitos aos estímulos ambientais); e o humanismo, que foca na autoaprendizagem e na axiologia que perpassa o exercício do aprender, são todos dinamizados em favor do desenvolvimento das competências.

No elenco das competências, cada projeto pedagógico de curso deve considerar o contexto socioeducacional em que está inserido, prospectando o preparo de um egresso apto a enfrentar os problemas contemporâneos. As instituições de ensino, assim, devem estar sensíveis às demandas dos segmentos acadêmicos (estudantes e professores) e da comunidade externa, tanto em âmbito local e regional quanto nacional e global. Cultivar esse diálogo respeitoso e democrático, com sujeitos e interesses tão heterogêneos, por vezes, antagônicos, se mostra um grande desafio, não apenas na educação jurídica. 
As políticas neoliberais, no cenário globalizado, têm promovido a comercialização da educação como um tipo de serviço, e não como um bem público e direito fundamental. Por sua vez, o Estado tende a reduzir seus investimentos na educação. As instituições de ensino, tanto públicas quanto privadas, passam a "negociar" o custo-benefício de suas ações, nem sempre de modo a priorizar as aprendizagens significativas. Tendo, como meta principal, o lucro ou a captação de recursos para seus projetos, a sobrevivência da organização passa pela competição mercadológica. Até métodos, temas e problemáticas sociais são apropriados, no ambiente educacional, segundo a lógica ou a tônica do mercado.

Se pensarmos nas ações afirmativas de inclusão de grupos, historicamente, menos presentes no espaço universitário (podemos aqui citar os negros, os indígenas e as pessoas com deficiência, que estão previstos na lei federal das chamadas “cotas”), o cenário é mais preocupante. O sistema de reserva de vagas, visando superar preconceitos e discriminações, pela privilegiada via educacional, traz as questões da diversidade étnico-racial, das desigualdades socioeconômicas e da acessibilidade como demandas urgentes para que haja equidade e efetiva permanência estudantil na universidade.

A articulação das políticas de identidade e de igualdade, no ambiente acadêmico, podem proporcionar um enriquecimento cultural que, se bem aproveitado, pela educação jurídica, tem o potencial para incrementar os processos de aprendizagem. A justiça cognitiva, que valoriza os diversos saberes, oferta perspectivas promissoras para o ensino do Direito, desenvolvido num ambiente de pluralidade.

Por fim, retomo o termo "crise" citado, inicialmente, para afirmar que, apesar de mudanças históricas do país, inclusive, com reformas universitárias e nas diretrizes curriculares nacionais, não podemos falar que o "ensino jurídico" um dia vivenciou uma "era dourada". Logo, o modelo não funcionava perfeitamente e, então, adveio uma “crise". O discurso da “crise" é uma forma retórica de apelar para utopias. Como o próprio nome indica, utopia é um não-lugar, um horizonte a ser trilhado.

Se queremos falar dos "desafios" e das "perspectivas do ensino jurídico no semiárido brasileiro", podemos dizer que eles passam por nutrir utopias e encarar obstáculos. Como os sertanejos nordestinos, não podemos abandonar a peleja. 